Arq. Bras. Med. Vet. Zootec., v.66, n.4, p.1089-1096, 2014

\title{
Aspectos morfológicos macro e microscópicos do estômago de tamanduá-mirim
} (Tamandua tetradactyla)

\author{
[Macroscopic and microscopic morphological aspects of \\ lesser anteater stomach (Tamandua tetradactyla)] \\ A.C.O. Pinheiro ${ }^{1}$, A.R. Lima ${ }^{1}$, A.F. Carvalho ${ }^{2}$, L.C. Pereira ${ }^{3}$, É. Branco ${ }^{1 *}$ \\ ${ }^{1}$ Universidade Federal Rural da Amazônia- UFRA - Belém, PA \\ ${ }^{2}$ Faculdade de Medicina Veterinária - Centro Universitário Octávio Bastos - Jardim Nova São João \\ ${ }^{3}$ Área de Mina Bauxita - Estrada Mineração - Paragominas, PA
}

\begin{abstract}
RESUMO
Diante do escasso conhecimento morfofisiológico do trato digestório do Tamandua tetradactyla, este trabalho pretendeu esclarecer a morfologia do estômago dessa espécie. Utilizaram-se seis espécimes, sendo três machos e três fêmeas jovens, provenientes da área de Mina Bauxita Paragominas - PA, doados, após morte por atropelamento, ao Laboratório de Pesquisa Morfológica Animal (LaPMA). Os animais foram fixados com solução aquosa de formaldeído (10\%), seguido de dissecação, avaliação da topografia do estômago, com posterior descrição, mensuração e coleta de material para microscopia. As análises topográfica e macroscópica revelaram que o estômago, unicavitário, com presença de pequena e grande curvaturas, estava localizado no antímero esquerdo da cavidade abdominal, ligado cranialmente ao esôfago e caudalmente ao duodeno, e apresentou um aumento de superfície na região pilórica (toro pilórico). Histologicamente, era constituído por epitélio colunar simples (região glandular), epitélio estratificado pavimentoso (região aglandular), lâmina própria, muscular da mucosa, submucosa, muscular circular interna, muscular longitudinal externa e serosa. A região do piloro apresentou um grande espessamento da camada muscular da mucosa, e foram observadas nesta região fossetas gástricas profundas. O estômago de $T$. tetradactyla revelou características morfológicas macroscópicas e histológicas semelhantes às espécies domésticas e selvagens.
\end{abstract}

Palavras-chave: Tamandua tetradactyla, morfologia, região gástrica

\begin{abstract}
Given the limited morphophysiological knowledge about the digestive tract of Tamandua tetradactyla, this study aimed to clarify the morphology of the stomach of this species. We used six young specimens, three males and three females, from the area of Paragominas bauxite mine - PA, donated after death by trampling, to the Research Laboratory Animal Morphological (LaPMA). The animals were fixed with an aqueous solution of formaldehyde (10\%), followed by dissection, evaluation of the topography of the stomach, with further description, measurement and collection of material for microscopy. The topographical and macroscopic analysis showed that the stomach was located in left on-timer of the abdominal cavity, connected entirely to the esophagus and caudally to the duodenum, was unicavitary with the presence of small and large curvature and showed a surface increase in the pyloric region (torus pylorus). Histologically it was composed of simple columnar epithelium (glandular region), stratified epithelium (aglandular region), lamina propria, muscular of mucous, submucous, muscular internal circular, muscular external longitudinal and serosa. The region of the pylorus presented a great thickening of the muscular layer of mucous, and deep gastric pits were observed in this region. The stomach of $\mathrm{T}$. tetradactyla revealed macroscopic and histological morphological characteristics similar to domestic and wild species.
\end{abstract}

Keywords: Tamandua tetradactyla, morphology, gastric region

Recebido em 16 de agosto de 2013

Aceito em 14 de dezembro de 2013

*Autor para correspondência (corresponding author)

E-mail: ebranco.ufra@gmail.com 


\section{INTRODUÇÃO}

O tamanduá- mirim (Tamandua tetradactyla), também chamado de tamanduá-de-colete, é um mamífero xenartro da família Myrmecophagidae e nativo da América do Sul. Esta espécie encontra-se ameaçada pela ação predatória do homem, pelas queimadas que eliminam sua fonte de alimento e por atropelamentos em rodovias que cruzam seu habitat natural (Cubas et al., 2006). São animais discretos e de hábitos noturnos, porém, por não se reproduzirem em cativeiro, pouco se sabe a respeito de sua reprodução. São vistos em pares na natureza apenas na época do acasalamento, e o período de gestação é de aproximadamente cinco meses. Insetívoros, alimentam-se sobretudo de cupins e formigas e apresentam baixos níveis metabólicos, que contribuem para os longos períodos de gestação. Possuem olfato bastante desenvolvido, língua longa, que auxilia na captura do alimento, e, por possuírem dentes rudimentares, o alimento é triturado no estômago (Tavares e Koenemann, 2008; Chinem, 2010).

Quanto ao estômago, objeto alvo deste estudo, é uma das principais porções do aparelho digestório, caracterizando-se como simples (glandular) ou composto (glandular e aglandular). O estômago simples ou glandular é um tubo muscular dilatado modificado, que assume uma configuração saculiforme quando preenchido com alimento, o qual é submetido à ação enzimática e hidrolítica do suco gástrico. A parede muscular do órgão induz à mistura mecânica e à quebra dos alimentos. Quanto à localização, situa-se caudalmente à esquerda do esôfago, possuindo uma pequena e uma grande curvatura. É constituído pela região do cárdia, pela região fúndica, pelo corpo e pela região do piloro (Frandson et al., 2005; Dyce et al., 2010).

Histologicamente, o estômago é constituído por quatro camadas ou túnicas: serosa, muscular, submucosa e mucosa, cada uma contribuindo para as funções digestivas que este órgão exerce. Essas túnicas variam pouco em seu desenvolvimento, não apenas entre espécies, mas também dentro de diferentes áreas do estômago (Banks, 1992).

Diante do escasso conhecimento morfofisiológico do Tamandua tetradactyla, objetivou-se esclarecer a morfologia do estômago, visando melhor compreensão fisiológica e nutricional dessa espécie.

\section{MATERIAL E MÉTODOS}

Foram utilizados seis espécimes de Tamandua tetradactyla, sendo três machos e três fêmeas jovens, provenientes da área de Mina Bauxita Paragominas - PA, sob autorização SEMA-PA No 455/2009 e 522/2009, doados, após morte por atropelamento, ao Laboratório de Pesquisa Morfológica Animal (LaPMA) da Universidade Federal Rural da Amazônia (UFRA).

Os animais, previamente criopreservados, foram descongelados em água corrente e, na sequência, fixados por meio da infusão intramuscular e intracavitária de solução aquosa de folmaldeído a $10 \%$, com posterior submersão dos animais em mesma solução, por um período mínimo de sete dias. A dissecação ocorreu com auxílio de instrumental básico a partir de incisão na linha alba, desde a cartilagem xifoide até próximo à genitália externa. Em seguida, avaliou-se a topografia do estômago, com posterior descrição, registros fotográficos, mensuração e coleta de material para microscopia de cada região gástrica. A mensuração foi realizada com o auxílio de paquímetro digital (Western ${ }^{\circledR}-$ PRO) e fita métrica, levando-se em consideração a luz do órgão, a espessura e o comprimento de suas curvaturas.

Os fragmentos coletados foram submetidos ao processo rotineiro histológico de desidratação e embebição em parafina, com posterior realização de cortes em micrótomo LEICA 2165, com espessura de $5 \mu \mathrm{m}$. Estes foram corados por hematoxilina e eosina (HE) (Tolosa et al., 2003) para as análises morfológica e estrutural. O material foi fotografado por meio de fotomicroscópio LEICA E - 400.

Toda nomenclatura adotada foi baseada na Nomenclatura Atômica e Histológica Veterinária (International..., 1994), (International..., 2006), (International..., 2012), e.

\section{RESULTADOS}

Os animais estudados apresentaram o estômago localizado no antímero esquerdo da cavidade abdominal, com formato sacular e ligado cranialmente ao esôfago e caudalmente ao duodeno (Fig. 1A). No órgão observou-se a 
mucosa com região glandular e aglandular (composto), com várias pregas gástricas, grandes e pequenas, distribuídas nas regiões do cárdia, fundo e região do piloro (Fig. 2A). A região do piloro mostrou-se com uma musculatura bastante reforçada e densa e apresentou um pequeno aumento ou protuberância da musculatura na entrada do duodeno (Fig. 2B). Além do formato sacular, o órgão apresentou uma pequena e uma grande curvatura (Fig. 1B). A Tab. 1 mostra as mensurações da grande e da pequena curvatura do estômago.


Figura 1. Tamandua tetradactyla. Fotomacrografias do estômago: A - in situ acomodado no antímero esquerdo. Notar a relação topográfica com esôfago (Ef), duodeno (D), baço (B), omento menor (OM) junto à pequena curvatura e ao fígado $(\mathrm{F})$. B - ex situ com as mesmas correlações topográficas de $\mathrm{A}$, além da pequena curvatura (seta contínua) e do pâncreas $(\mathrm{P})$ junto à grande curvatura (seta interrompida). Barra de escala: $1 \mathrm{~cm}$.

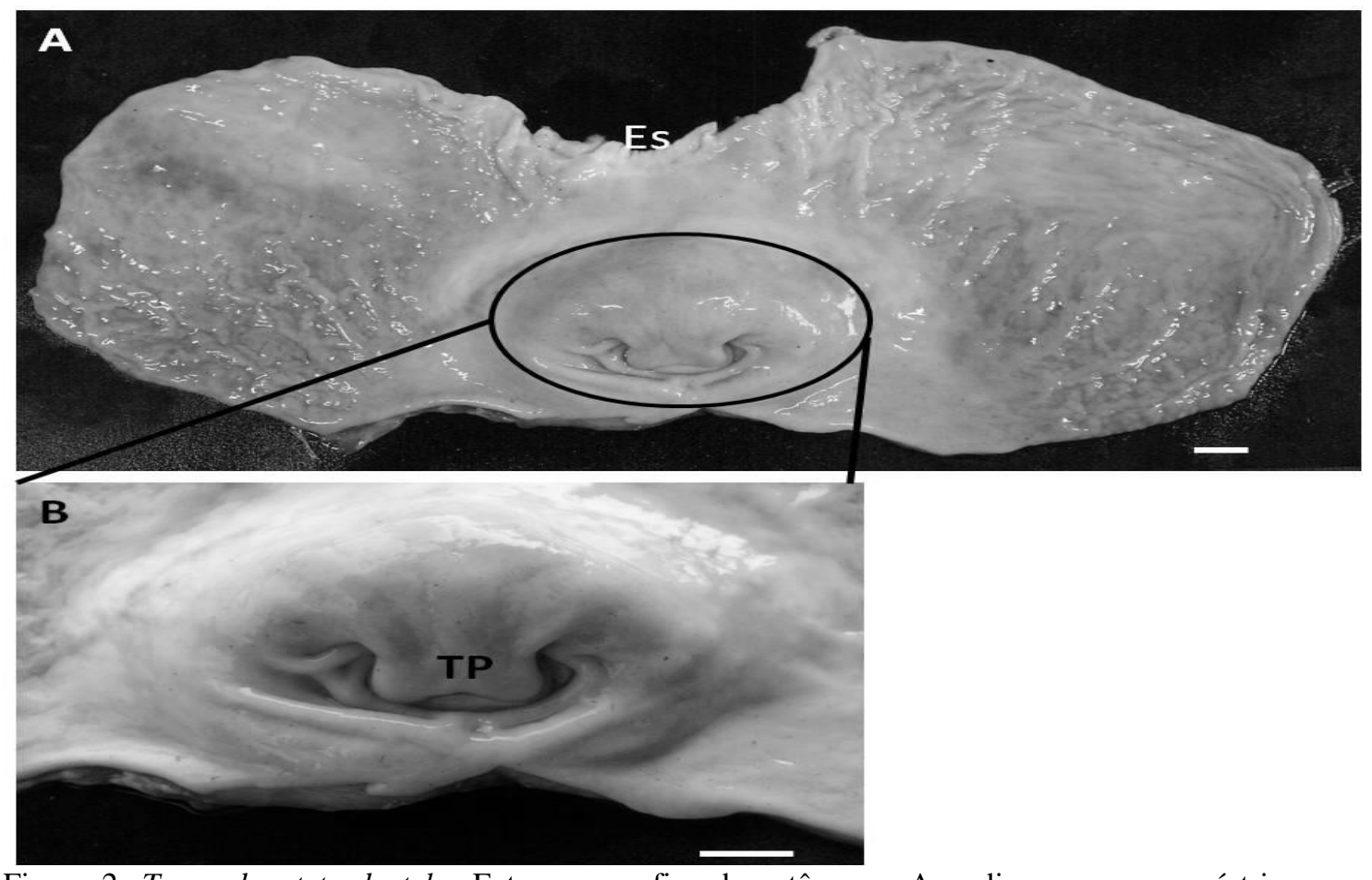

Figura 2. Tamandua tetradactyla. Fotomacrografias do estômago: A - diversas pregas gástricas nas paredes do órgão, a partir da região do cárdia, junto ao esôfago (Es). B - no detalhe, região pilórica, com uma musculatura mais densa. Presença de toro pilórico (TP). Barras de escala: $1 \mathrm{~cm}$. 
Tabela 1. Mensuração total da grande e da pequena curvatura do estômago de Tamandua tetradactyla

\begin{tabular}{lcc}
\hline & $\begin{array}{c}\text { Grande } \\
\text { curvatura } \\
(\mathrm{cm})\end{array}$ & $\begin{array}{c}\text { Pequena } \\
\text { curvatura } \\
(\mathrm{cm})\end{array}$ \\
\hline Macho & & \\
1 & 12 & 3 \\
2 & 11 & 4 \\
3 & 14 & 3 \\
Média & 12,33 & 3,33 \\
Desvio- & 1,24 & 046 \\
padrão & & \\
\hline Fêmea & & 3 \\
\hline 1 & 7 & 3 \\
2 & 11 & 3 \\
3 & 14 & 3 \\
Média & 10,66 & 0 \\
Desvio- & 2,49 & \\
padrão & & \\
\hline
\end{tabular}

Histologicamente, o estômago de T. tetradactyla apresentou as seguintes camadas: epitélio colunar, lâmina própria, muscular da mucosa, submucosa, muscular circular interna, muscular longitudinal externa e serosa. Um epitélio simples colunar estava revestindo a luz do órgão; a lâmina própria era constituída de tecido conjuntivo e variou de espessura de acordo com a região observada (Fig. 3, 4 e 5).

A camada muscular situa-se profundamente à lâmina própria e é constituída de tecido muscular liso com fibras circulares e longitudinais. Essas três camadas juntas constituem a camada mucosa do estômago. A submucosa, constituída de tecido conjuntivo, é bem mais espessa que a lâmina própria e possui muitos vasos e nervos. As camadas musculares são típicas, formando uma mais interna, denominada muscular circular interna, e outra mais externa, denominada muscular longitudinal externa, ambas de tecido muscular liso.
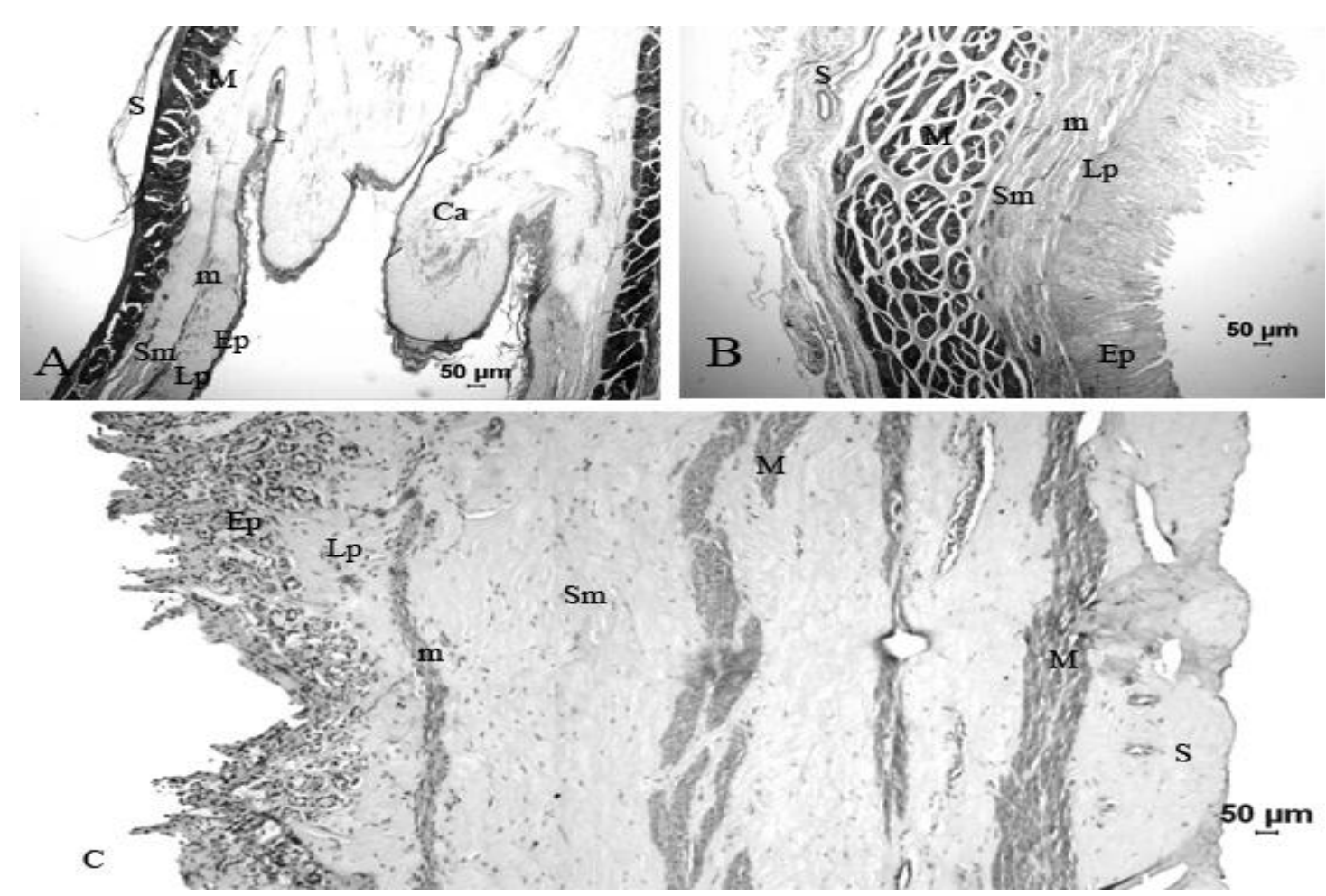

C

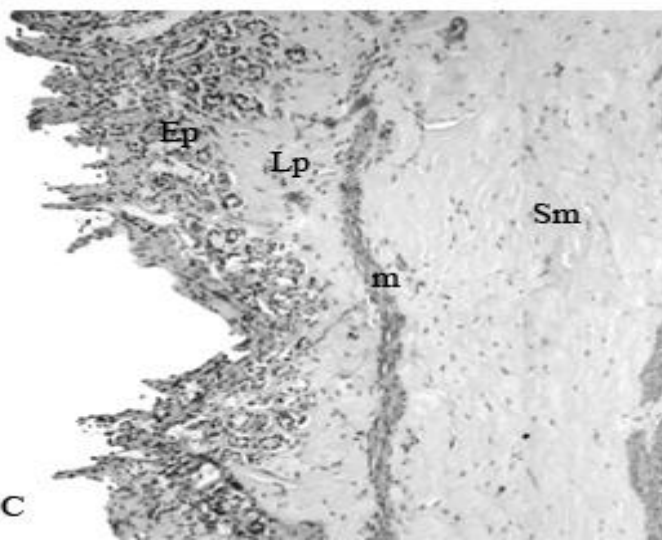

Figura 3. Tamandua tetradactyla. Fotomicrografias da região aglandular e da região cárdica. Em A, B e $\mathrm{C}$, observar as camadas histológicas características do aparelho digestório: Ep epitélio, Lp lâmina própria, m muscular da mucosa, Sm submucosa, M musculares (circular interna e longitudinal externa) e S serosa. Em A, o Ep epitélio é estratificado pavimentoso levemente queratinizado, evidenciando a região aglandular do estômago, e em B e C o epitélio é colunar, formando as fossetas gástricas das glândulas cárdicas. Em A, observar Ca, região do cárdia. Em B e C, região cárdica do estômago. Coloração HE. 

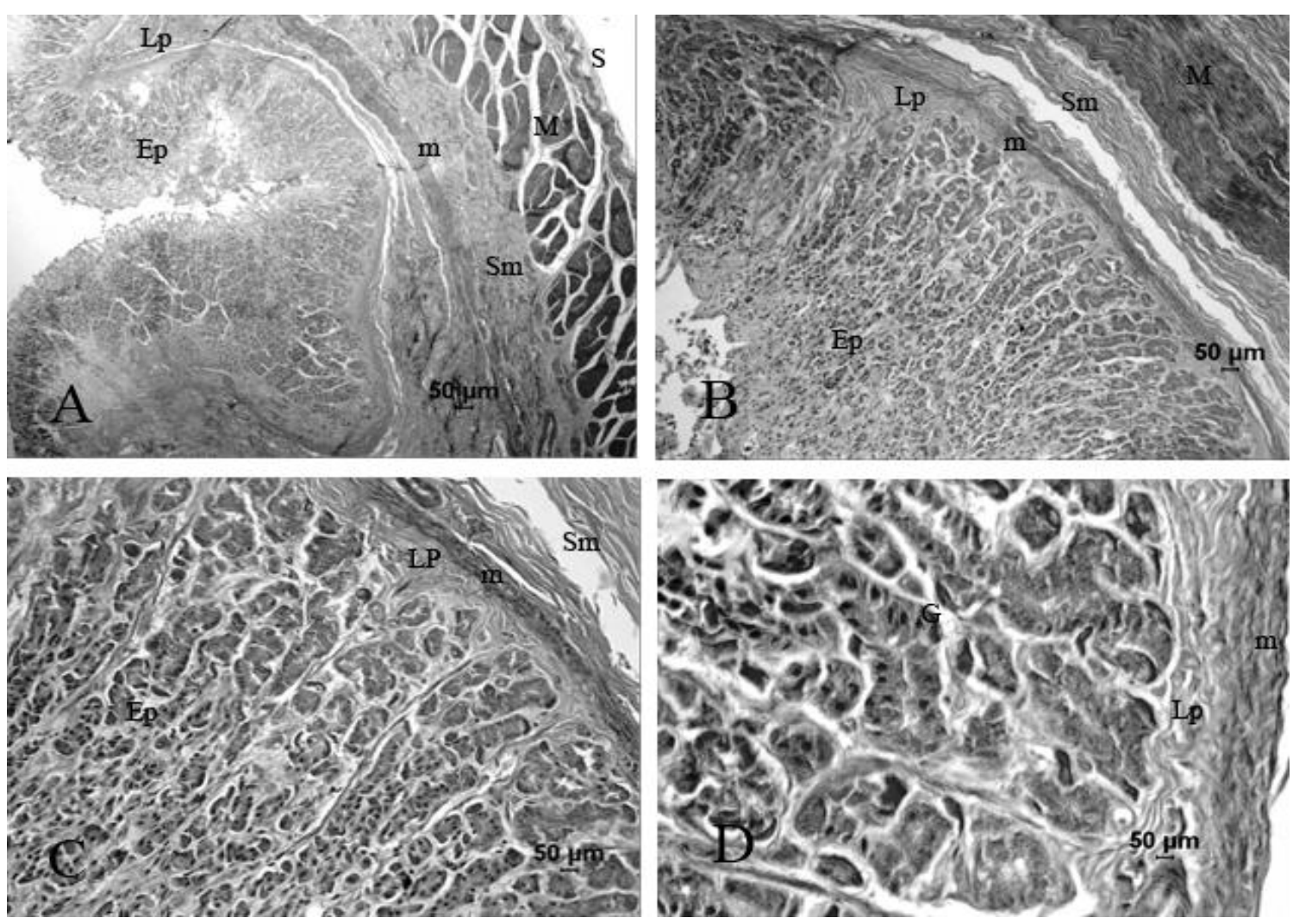

Figura 4. T. mirim. Fotomicrografias da região fúndica do estômago. Notar todos os estratos histológicos do sistema digestório presentes em A, B, C e D: Ep epitélio colunar, Lp lâmina própria, m muscular da mucosa, Sm submucosa, M muscular, S serosa. Em D, observar em $\mathrm{G}$ detalhe das glândulas fúndicas, com células parietais mais claras e zimogênicas mais escuras. Coloração HE.

Revestindo externamente o estômago, observouse a serosa, constituída de epitélio simples pavimentoso e tecido conjuntivo. A região aglandular do estômago do tamanduá-mirim apresentou-se pequena e restrita à região esofágica do estômago, caracterizado por epitélio estratificado pavimentoso. Logo a seguir, iniciase a região das glândulas cárdicas, cujo epitélio colunar simples forma as fossetas gástricas, das quais as bases são as glândulas cárdicas e tubulares compostas. Nesta região, encontram-se as células principais ou zimogênicas e as células parietais ou oxínticas (Fig. 3). Além desses dois tipos celulares, encontram-se células mucosas do colo, que revestem o colo da glândula. A região pilórica do estômago do tamanduá-mirim possui glândulas mais curtas, cujas fossetas são mais longas. As glândulas são do tipo tubular simples e assemelham-se às cárdicas. Na região pilórica, ocorre um espessamento da camada muscular, formando o piloro (Fig. 5).

\section{DISCUSSÃO}

Os estudos morfológicos do aparelho digestório de espécies da ordem Xenarthra, como o tamanduá-mirim, ainda são escassos, portanto fazem-se necessárias pesquisas avançadas sobre parâmetros morfométricos e morfológicos nessa área, para fornecer subsídios aos estudos posteriores e conhecer os processos digestivos e a alimentação adequada para cada espécie.

Topograficamente, o estômago de $T$. tetradactyla assemelhou-se às diversas espécies domésticas e selvagens e revelou-se unicavitário, como observado nos mamíferos monogástricos (Getty, 1986; Dyce et al., 2010). 


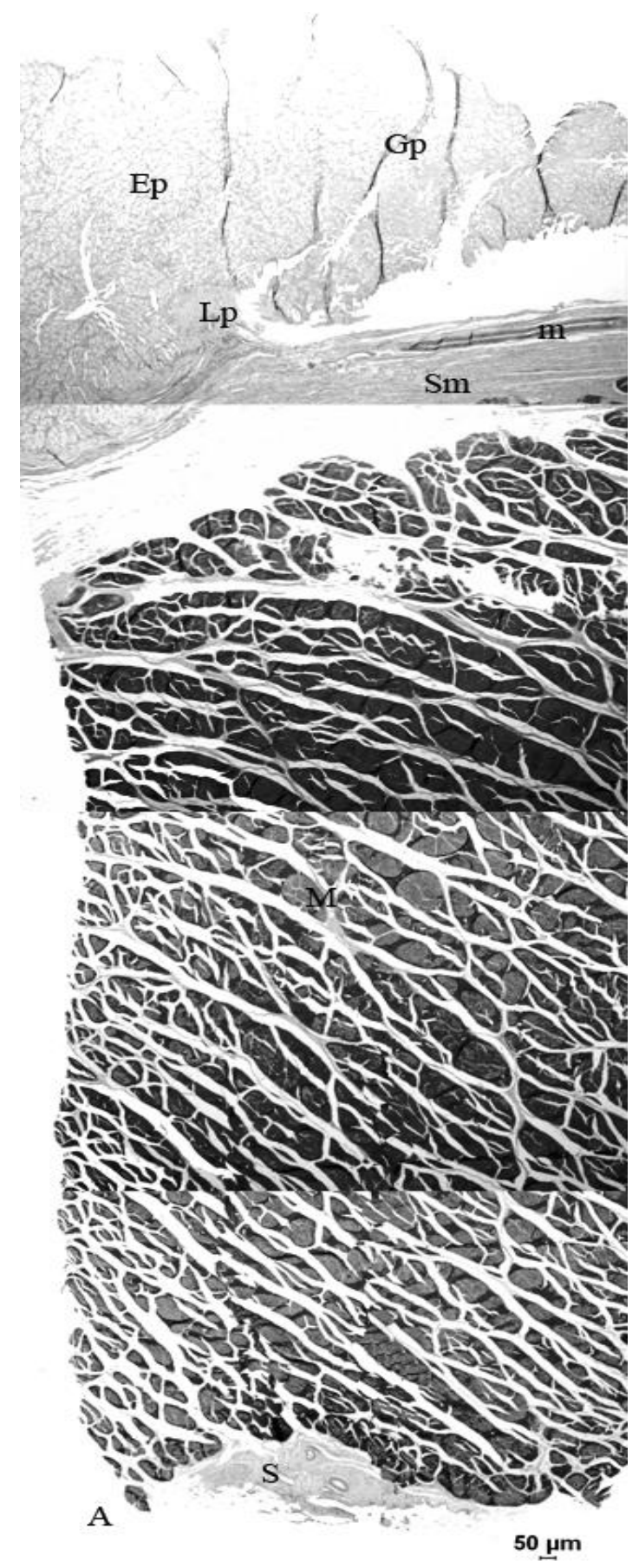

Figura 5. T. mirim. Fotomicrografias da região pilórica do estômago. Ep epitélio, Lp lâmina própria, m muscular da mucosa, Sm submucosa, M musculares (circular interna e longitudinal externa) e S serosa. Observar em Gp glândulas pilóricas tubulares simples ou ramificadas. As fossetas são mais longas, e as glândulas mais curtas nesta região. Coloração HE.
Nos mamíferos, existe uma diversidade considerável na forma e na estrutura quanto ao aparelho digestório. Muitas dessas distinções são adaptativas e refletem a alimentação habitual dos vários grupos de animais. Por exemplo, a dieta concentrada de carnívoros é digerida com mais facilidade, e estes animais possuem um estômago pequeno e simples. Os herbívoros (ruminantes), que possuem uma alimentação rica em carboidratos complexos (celulose), necessitam de uma grande câmara de fermentação, onde o alimento possa ser mantido em um ambiente favorável para a multiplicação e atividade dos micro-organismos, que irão degradar tais carboidratos (Dyce et al., 2010). No Tamandua tetradactyla, por ser um animal que se alimenta de pequenos insetos, encontrou-se um compartimento gástrico unicavitário, pequeno, de formato sacular (possuindo uma pequena e uma grande curvatura), diferentemente do que foi descrito para a preguiça (Bradypus torquatus), que apresentou estômago volumoso em relação a outros órgãos da cavidade peritoneal, formando as seguintes regiões: cárdica, fúndica e pilórica (Rezende et al., 2011). A região cárdica está subdividida em três sacos: direito, médio e esquerdo; a região fúndica é representada por um saco lateral direito e termina com um divertículo; a região pilórica é subdividida em região prépilórica I (glandular) e pré-pilórica II (muscular). Apesar de pertencerem à mesma ordem, essa diferença ocorre devido à distinta alimentação dessas espécies: a preguiça é um animal herbívoro, por isso necessita de um estômago compartimentado e maior, para que ocorra a fermentação dos micro-organismos; o tamanduámirim, como insetívoro, tem a capacidade de suprir suas necessidades digestivas com um estômago unicavitário.

Alguns autores, como Getty (1986) e Dyce et al. (2010), descreveram a presença de um toro pilórico em mamíferos domésticos (bovino e suíno). Essa estrutura é uma protuberância carnosa, que consiste em músculo liso e tecido adiposo. Dyce et al. (2010) afirmaram que sua função é incerta, mas Getty (1986) relatou que ele exerce ação ativa e passiva no fechamento completo do óstio pilórico, no qual o toro encaixa-se entre as extremidades livres do músculo semilunar do esfíncter do piloro, agindo como uma tampa. Uma estrutura semelhante a esta foi observada no final do antro pilórico do estômago do tamanduá-mirim. Esta poderia 
auxiliar no fechamento do esfíncter, como afirma Getty (1986), nas espécies domésticas, impedindo o trânsito livre dos insetos ingeridos diretamente para o intestino, o que favoreceria o processo de digestão desses animais.

Todas as regiões do estômago do tamanduámirim observadas sob microscopia de luz estavam organizadas com as camadas histológicas características nos animais domésticos (Samuelson, 2007). O estômago do mocó (Kerodon rupestris) apresentou uma reduzida região aglandular, a qual se restringiu à transição gastroesofágica, onde se observou epitélio estratificado pavimentoso. Este epitélio se modifica para um epitélio cilíndrico simples na região glandular (Borsari et al., 2010). A mesma estrutura foi observada no $T$. tetradactyla, mas a região glandular é caracterizada por um epitélio colunar simples. Apesar de uma restrita região aglandular, Borsari et al. (2010) consideraram o estômago de mocó como composto, assim como nos animais avaliados neste estudo.

Semelhantemente ao encontrado no estômago do T. tetradactyla, Ofusori et al. (2008) descreveram no estômago de pangolin (Manis tricuspis) um revestimento epitelial colunar simples na região glandular (corpo e piloro), com exceção das regiões do cárdia e fundo (aglandular), que apresentaram principalmente um epitélio estratificado escamoso queratinizado. Ofusori et al. (2008) relataram ainda que esse epitélio estratificado escamoso queratinizado provavelmente oferece uma proteção contra a ulceração proveniente da ingesta quitinosa (formigas e térmitas) do pagolin, que, assim como o tamanduá-mirim, é um insetívoro, e que tal região pode também ser sítio ativo para as atividades mecânicas do estômago. No $T$. tetradactyla, não se pode afirmar essa proteção, pois, apesar de o epitélio da região aglandular ser estratificado e levemente queratinizado, esta região é muito pequena e se restringe à região esofágica do estômago.

Vários autores (George et al., 1998; Rocha e Lima, 1998; Junqueira e Carneiro, 1999) descreveram a túnica mucosa do estômago muscular das aves com um revestimento epitelial colunar simples, na lâmina própria, glândulas tubulares simples ou ramificadas e a presença de uma túnica muscular bem desenvolvida, que distingue basicamente duas camadas de músculo liso, uma camada circular interna mais grossa e uma camada longitudinal externa mais estreita. A mesma descrição foi revelada no presente estudo, mas o espessamento da camada muscular é característico na região pilórica do estômago do T. tetradactyla. Contrariando tais autores, Catroxo et al. (1997) encontraram no ventrículo do cardeal vermelho (Paroaria gularis) um epitélio prismático simples, e Illanes et al. (2006), no ventrículo de avestruz, um revestimento epitelial cilíndrico simples. O tamanduá-mirim, assim como as aves, não possui dentes, por isso seu alimento precisa ser quebrado no estômago para que seja digerido. Uma musculatura reforçada se faz necessária para auxiliar na contração do órgão e na trituração dos alimentos. Estudos mais aprofundados precisam ser desenvolvidos sobre a questão histológica e o poder de contração desse órgão.

\section{CONCLUSÃO}

O estômago do Tamandua tetradactyla apresentou características morfológicas, topográficas e camadas histológicas presentes em outras espécies domésticas e selvagens, destacando o epitélio colunar simples na região glandular e uma musculatura espessa na região pilórica, características descritas no ventrículo de aves e no estômago de outros insetívoros.

\section{REFERÊNCIAS}

BANKS, W.J. Histologia veterinária aplicada. 2.ed. São Paulo: Manole, 1992. p.437-39.

BORSARI, F.N.; MARTINS, L.L.; REIS, A.C.G. et al. Análise macroscópica e microscópica do estomago do Mocó (Kerodon rupestris). Rev. Pubvet., v.4, Ed.128, Art. 868. 2010.

CATROXO, M.H.B.; LIMA, M.A.I.; CAPPELLARO, C.E.M.P.D.M. Histological aspects of the stomach (proventriculus and gizzard) of the red-capped cardinal (Paroaria gularis gularis, Linnaeus, 1766). Rev. Chil. Anat., v.15, p.19-27, 1997.

CHINEM, S. Tamanduá-mirim. Fundação parque zoológico de São Paulo. 2010 Disponível em: <http://www.zoologico.sp.gov.br/mamiferos/tamandua mirim.htm>. Acessado em: 15 ago. 2011.

CUBAS, Z.S.; SILVA, J.C.R.; CATÃO-DIAS, J.L. Xenarthra (Tamanduá, Tatu, Preguiça). Tratado de animais selvagens - medicina veterinária. São Paulo: Roca, 2006. 1376p. 
DYCE，K.M.; SACK，W.O.; WENSING，C.J.G. Tratado de Anatomia Veterinária. 4. ed.. Rio de Janeiro: Elsevier, 2010. 872p.

FRANDSON, R.D.; WILKE, W.L.; FAILS, A.D. Anatomia e Fisiologia dos Animais de Fazenda. 6.ed. Rio de Janeiro: Guanabara Koogan, 2005. 160p.

GEORGE, L.L.; CARLOS, E.R.A.; CASTRO, R.R.L. Histologia Comparada. 2.ed. São Paulo: Roca, 1998. 298p.

GETTY, R. Anatomia dos animais domésticos. 5.ed. Rio de Janeiro: Guanabara Koogan, 1986. 2v. 1001p.

ILLANES, J.; FERTILIO, B.; CHAMBLAS, M. et al. Descripción histológica de los diferentes segmentos del aparato digestivo de avestruz (Struthio camelus var. domesticus). Int. J. Morphol., v.24, p.205-214, 2006.

INTERNATIONAL Commitee on Veterinary Histological Nomenclature. Nômina histological (Together with Nômina anatômiva veterinária). 2.ed. rev. Zurich: Word Association on Veterinary Anatomists, 1994. 190p.

INTERNATIONAL Committee on Veterinary Embriological Nomenclature. Nômina Embryologica Veterinaria . 2.ed. Knoxville: Word Association on Veterinary Anatomists, 2006. 47p.

INTERNATIONAL Committee on Veterinary Gross Anatomical Nomenclature. Nomina anatômica veterinária. 5. ed. Knoxville: World Association on Veterinary Anatomist, 2012. 160 p.
JUNQUEIRA， L.C.; CARNEIRO， J. Histologia Básica. 9.ed. Rio de janeiro: Guanabara Koogan, 1999. 427p.

OFUSORI, D.A.; CAXTON, M.E.A.; KEJI, S.T. et al. Adaptaciones Microarquitecturales en el del Estômago Pangolin Africano (Manis tricuspis). Int. J. Morphol., v.26, p.701-705, 2008.

REZENDE, L.C.; MONTEIRO, J.M.; CARVALHO, P. et al. Morfologia y de los Vascularización Compartimentos Gástricos en Osos Perezosos de Tres Dedos (Bradypus torquatus Illiger, 1811). Int. J. Morphol., v.29, p.1282-129, 2011.

ROCHA, S.O.; LIMA, M.A. Aspectos histológicos del estomago de la lechuza (Speotyto cunicularia, Molina, 1782). Rev.Chil. Chil.Anat., 16(2) :191-197, 1998. Anat. v.16, p.191-197, 1998.

SAMUELSON, D.A. Tratado de histologia veterinária. 1. ed.. Editora: Elsevier, 2007. 554p.

TAVARES, S.V.; KOENEMANN, J.G. Ocorrência de Tamandua tetradactyla (Linnaeus, 1758) (Xenarthra, Myrmecophagidae) no município de Itaqui, fronteira oeste do Rio Grande do Sul, Brasil. Rev. Biod. Pamp. v.6, p.30-33, 2008.

TOLOSA, E.M.C.; RODRIGUES, C.J.; BEHMER, A.O.; FREITAS-NETO, A.G. Manual de técnicas para histologia normal e patológica. 2. ed., São Paulo: Manole, 2003. 37p. 